\title{
Okul Öncesi ve İlkokul Sınıf Öğretmenlerinin Bireysel Yenilikçilik Düzeyleri ve Onamsız Öğrenme Ortamları Tercihlerinin İncelenmesi ${ }^{1}$
}

\author{
DOI: 10.26466/opus.598991
}

\begin{abstract}
*
$\underline{\text { Kamil Arif Kırkıç }}^{*}$ - Büşra Topal**

* Dr. Öğr. Üyesi İstanbul Sabahattin Zaim Üniversitesi, Eğitim Fakültesi, Eğitim Bilimleri Bölümü, E-Posta: kamil.kirkic@izu.edu.tr

ORCID: $0000-0002-8902-437 X$

** Öğretmen, MEB, Ataşehir / İstanbul

E-Posta : busratp1053@gmail.com

ORCID: $\quad \underline{0000-0001-6256-3827}$

Öz

Bu araştırmanın amacı okul öncesi ve ilkokul sınıföğretmenlerinin bireysel yenilikçilik özelliklerine göre onamsız öğrenme ortamları tercihlerinin incelenmesidir. Bu araştırmada nicel araştırma modellerinden betimsel tarama yöntemi kullanılmıştır. Araştırmanın evreni İstanbul il Milli Eğitim Müdürlüğüne bağhl resmi ve özel; okul öncesi ve ilkokul kurumlarındaki toplam 7644 öğretmen, örneklemini 384 öğretmen oluşturmuş̧ur. Araştırmada veri toplamak amacıyla, "Bireysel Yenilikçilik Ölçeğgi", araştırmacı tarafindan geliştirilmiş olan "Kişisel Bilgi Formu" ve "Onamsız Öğrenme Tercihleri Formu" kullanılmıştır. Verilerin analizinde ki-kare ilişki testi kullanılmıştır. Araştırma bulgularına göre öğretmenler en çok Sorgulayıcı (\%38,3), sonrasında Öncü (\%36,8), daha sonra Yenilikçi $(\% 14,2)$, Kuşkucu $(\% 7,8)$ ve Gelenekçi $(\% 2,9)$ kategorilerinde toplanmıştır. Okul öncesi öğretmenlerde Gelenekçi kategorisinde yer alan bulunmamaktadır. Sorgulayıcı ve Öncü kategorilerinde okul öncesi öğretmenlerinin oranı sinıf öğretmenlerinden daha yüksektir. Gelenekçi kategorisinde erkek oranı daha yüksek, Kuşkucu kategorisinde kadın oranı daha yüksektir. Yaş, eğitim, çalışma süresi değişkenlerine göre yenilikçilik düzeyleri farklılaşmamaktadır. Farklı yenilikçilik seviyesinde olanlar arasında onamsı öğrenme yolların tercih açısından bir farklılık bulunmamaktadır
\end{abstract}

Anahtar Kelimeler: Bireysel yenilikçilik, Onamsız öğrenme, Okul öncesi öğretmeni, İlkokul sınıf öğretmeni

\footnotetext{
${ }^{1}$ Makale Kamil Arif Kırkıç danışmanlığında tamamlanmış olan Buşra Topal'ın yüksek lisans projesinden üretilmiştir.
} 


\title{
Investigating Pre-school and Primary School Teachers' Preferences of Informal Learning Environments and Their Individual Innovativeness Levels
}

\begin{abstract}
The aim of this study is to examine the preferences of the pre-school and primary school teachers according to their individual innovativeness levels. In this research, descriptive survey method that is one of the quantitative research models is used. The population of interest is 7644 teachers who work in preschool and primary schools of İstanbul. The sample of the study is composed of 384 teachers. Individual Innovativeness Scale, Demographic Information Form and Informal Learning Preferences Form that had been developed by the researcher were used as data collection instruments. Chi-square relationship test was used to analyze the data. According to the findings of the research, the teachers were the most Inquisitive (38.3\%), then the Leader (36.8\%), then Innovative (14.2\%), Skeptic $7.8 \%$ ) and Traditionalist $(2.9 \%)$. In the inquisitive and the leader categories, the proportion of pre-school teachers is higher than that of classroom teachers. In the traditionalist category, the proportion of men is higher and the rate of women in the skeptic category is higher. The innovativeness levels of teachers did not differ according to age, education and working time variables. There is no difference in terms of preference among the ones with different levels of innovation
\end{abstract}

Keywords: Individual innovativeness levels, Informal learning environments, Pre-school teacher, Primary school teacher 


\section{Giriş}

Günümüzde her gün yeni bir teknolojik gelişme olmakta, yeni fikirler ortaya atılmakta, bilimdeki gelişmeler sonucu eski bilinenler değişmektedir. $\mathrm{Bu}$ gelişmeler yenilik; bireyin yeniliği hayatına aktarması ise yenilikçilik olarak adlandırılmaktadır (Handa ve Gupta, 2009). Bireysel yenilikçilik ise bireylerin yenilikçilik hususunda ortaya koydukları farklılıkları ifade eder. Her birey eşit derecede yenilikçi değildir. Rogers (1995), kişileri yenilikçilik seviyeleri açısından Yenilikçi, Öncü, Sorgulayıcı, Kuşkucu ve Gelenekçi olarak beş gruba ayırmıştır. Bir yeniliği sorgulamadan kabul edenler Yenilikçi; önder olarak toplumun önünden gidenler Öncü olarak sınıflandırılırken, Sorgulayıcılar yeniliğe karşı olmayıp temkinli davrananlardır. Kuşkucular uzun süre yeniliği kabul etmeyen veya imkânı olmadığı için gereksiz görenlerdir. Gelenekçiler ise geçmişle bağlarını koparacağı şüphesiyle yeniliğe karşı çıkarlar. Yenilikçi özelliğe sahip kişiler hayatları ile yeniliği bütünleştirirken, öğrenme süreçlerini geleneksel yollar olan okullarda, enstitülerde gerçekleştirmelerinin yanında yenilikçi olmaları nedeniyle kimi zaman farklı ögrenme ortamlarından da yararlanmaları olasıdır.

Birey için öğrenme doğumdan ölüme kadar devam eder. Öğrenme isteğiyle doğan insanoğlu, öğrenmeye çevresini inceleyerek, sonrasında ailesini taklit ederek başlar, büyüdükçe öğrenme kaynakları ve yolları çeşitlenir. Öğrenme yolları temelde, eğitimin amacına, eğitim kaynağına, hedefi olup olmamasına göre onamlı (İngilizce: Formal) ve onamsız (İngilizce: Informal) olarak ikiye ayrılır. Onamlı öğrenme, okullar, dershaneler, kurslar gibi kurumsal yapılar altında verilir, bir amacı vardır ve program çerçevesinde şekillendirilmiştir (Hager ve Halliday, 2009; Oktay, 2009). Onamsız öğrenme ise hayat içerisinde kendiliğinden olan, programı olamayan, kurumsal bir yapı altında verilmeyen tüm öğrenmeleri içerir. Dil öğrenme, sosyal ilişkileri öğrenme, okunan gazeteden, izlenen filmden, kullanılan sosyal medya hesaplarından edinilen kazanımlar bu kapsamdadır. Onamsız öğrenmeler onamlı öğrenmeden bağımsız kazanımların yanında onunla birlikte de meydana gelebilmektedir. Çocuk okulda bir matematik formülünün yanında, insanlarla iletişim kurmayı, dostluğu da öğrenir (Oktay, 2009; Schugurensky, 2000). 
Onamsız öğrenmeler okullardan bağımsız evde, işyerinde veya sosyal çevresinde gerçekleşir. Bireyin TV izlerken, kitap okurken, eğlenirken veya gezerken kazandığı bilgi ve beceriler bu kapsamda yer alır. Onamsız öğrenmelerde öğrenme süresini bireyin kendisi belirler. Merak ettiği bir konuyu öğrenmek için motive olmuş biçimde saatlerini araştırmak, okumak için bilgisayar başında harcayabilir (Oktay, 2009). Bilginin ne kadar derinlemesine öğrenileceğine karar veren de yine bireyin kendisidir. Birey isterse konuyu yüzeysel öğrenmeyi tercih edebilir, isterse de çok derinlemesine öğrenebilir. Onamsız öğrenme, onamlı öğrenmedeki gibi bir belgeyle sonuçlanmaz. Fakat bu bilgiyle kendini kanıtlayarak iş bulabilir, sorunlarını çözebilir veya genel kültürünü artırabilir (McGivney, 2006; Şimşek Laçin, 2011).

Onamsız öğrenme kavramı ile ilgili farklı tasnifler bulunmaktadır. (Eraut, 2004; Bennett, 2012). Eraut (2004) onamsız öğrenmeyi örtük, tepkisel ve niyete bağlı olarak üçe ayırır. Örtük öğrenmede bireyin herhangi bir öğrenme amacı yoktur ama yaşantı içerisinde kendiliğinden öğrenir. Amerikan filmleri izleyenlerin eyalet isimlerini rahatlıkla sayabilmesi buna örnek verilebilir. Tepkisel öğrenmede kişi öğrendiğinin farkında olmakla birlikte bunu amaçlı olarak yapmamaktadır. Öğrenme süreci bitmeden sona erdirebilir çünkü net bir öğrenme hedefi yoktur. Yaşadığı ortamda Niyete bağhl öğrenme ise kişinin isteyerek, planlı bir biçimde öğrenmesidir. Örneğin, yabancı bir dili öğrenmek için karar verip hiçbir kursa gitmeden kendini bu konuda geliştirmesidir.

Bennett (2012) onamsız öğrenmeyi, öz-yönelimli öğrenme, rastlantısal öğrenme, örtük öğrenme ve bütünleştirici öğrenme olarak dörde ayırmaktadır. Öz yönelimli öğrenme, bireyin öğrenmeyi istemesi ve bu konuda çalışma yaparak öğrenmesidir. Rastlantısal öğrenmede birey bilinçli olarak öğrenme gayreti içerisinde bulunmaz ama süreç sonunda öğrendiğinin farkına varır. Bireyin günlük hayatta farkına varmadan öğrendiği ve öğrendiğinin de farkında olmadığı kazanımlardır. Örneğin, görgü kurallarının öğrenilmesi bu kapsama alınabilir. Bütünleştirici öğrenme ise tıpkı bireyin zihninde bir ampulün yanması misali çözüm yolunu keşfetmesidir. Birey sorunu çözmek için araştırma yapar ama bir yol bulamaz ama bir süre sonra çözüm yolu aklına geliverir. Bununla birlikte farklı yenilikçilik düzeyindeki kişilerin kullandıkları onamsız öğrenme yollarına ilişkin her- 
hangi bir araştırma yer almamaktadır. Bilgi evlerinde öğrenim gören öğrenciler ile yapılan çalışmada, onamsız öğrenme ortamlarında gerçekleştirilen etkinliklerin öğrencilerin öğrenmesini olumlu yönde etkilediği ve öğretim yapılan konuda bilinçlendirdikleri belirlenmiştir (Çavuş, Umdu Topsakal ve Öztuna Kaplan, 2016). Diğer bir çalışmada ise onamsız öğrenme ortamlarını kullanmada öğretmenlerin yeterli bilgi ve beceriye sahip olmadığı belirlenmiştir (Türkmen, 2015).

Onamsız öğrenme ortamlarının onamlı öğrenme ortamlarından daha farklı bir öğrenme düzeyi oluşturmadığını ortaya koyan çalışmalardan alan yazında bulunmaktadır.(Gürbüz, Kışoğlu ve Erkol, 2007).

Yenilikçiliğin farklı değişkenlerle ilişkisine yönelik ulusal (Bitkin, 2012; Demirel ve Seçkin 2008; Erdil v.d., 2017; Gürbüz, 2015; Kaya, 2017; Özçatalbaş, 2014; Tirpan, 2016; Yılmaz, 2013) ve uluslararası (Davis ve diğ., 1989; Handa and Gupta, 2009; Moore and Benbasat, 1991; Rogers, 2003; Surry \& Brennan 1998; Venkatesh, Thong ve Xu, 2012) alan yazında çok sayıda araştırma bulunmaktadır.

Araştırma bulgularına göre öğretmenler en çok Sorgulayıcı $(\% 38,3)$, sonrasında Öncü $(\% 36,8)$, daha sonra Yenilikçi $(\% 14,2)$, Kuşkucu $(\% 7,8)$ ve Gelenekçi $(\% 2,9)$ kategorilerinde toplanmıştır. Okul öncesi öğretmenlerde gelenekçi kategorisinde yer alan bulunmamaktadır. Sorgulayıcı ve öncü kategorilerinde okul öncesi öğretmenlerinin oranı sınıf öğretmenlerinden daha yüksektir. Gelenekçi kategorisinde erkek oranı daha yüksek, kuşkucu kategorisinde kadın oranı daha yüksektir. Yaş, eğitim, çalışma süresi değişkenlerine göre yenilikçilik düzeyleri farklılaşmamaktadır. Farklı yenilikçilik seviyesinde olanlar arasında onamsız öğrenme yollarını tercih açısından bir farklılık bulunmamaktadır.

Çalı̧̧ma okul öncesi ve ilkokul öğretmenlerinin bireysel yenilikçilik düzeylerini ve tercih ettikleri onamsız öğrenme ortamların belirlemenin yanında arasında bireysel yenilikçilik düzeylerine göre tercih ettikleri onamsız öğrenme ortamlarının neler olduğunun ortaya konulması hedeflenmiştir.

Çalışmanın temel amacı okul öncesi ve ilkokul sınıf öğretmenlerinin bireysel yenilikçilik özelliklerinin ve onamsız öğrenme ortamları tercihlerinin incelenmesidir. Araştırmamızda aşağıdaki sorulara yanıtlar aranmiştır: 
- Okul öncesi ve sınıf öğretmenlerinin bireysel yenilikçilik kategorilerine göre dağılımları nasıldır?

- Okul öncesi ve sınıf öğretmenleri arasında bireysel yenilikçilik düzeyleri açısından fark var mıdır?

- Öğretmenlerin yenilikçilik düzeyleri öğretmenlerin çeşitli özelliklerine göre farklılaşmakta mıdır?

- Öğretmenlerin onamsız öğrenme tercihleri yenilikçilik düzeylerine göre değişmekte midir?

\section{Yöntem}

$\mathrm{Bu}$ araştırmada nicel araştırma deseni kapsamında yer alan betimsel tarama modeli kullanılmıştır. Bu modelde var olan bir durumun bir zaman dilimi içerisinde olduğu haliyle, herhangi bir müdahalede bulunmadan betimlenmesi söz konusudur (Büyüköztürk ve diğ., 2017). Bu çalışmada öğretmenlerin bireysel yenilikçilik düzeyleri ve onamsız öğrenme tercihleri ölçülmüş ayrıca öğretmenlerin bireysel yenilikçilik düzeylerine göre onamsız öğrenme tercihlerinin nasıl değiştiği belirlenmiştir.

\section{Evren ve Örneklem}

Araştırmanın evreni İstanbul İl Milli Eğitim Müdürlüğüne bağlı resmi ve özel; okul öncesi ve ilkokul kurumlarındaki toplam 7644 öğretmen, örneklemini 384 öğretmen oluşturmuştur. Araştırmanın örneklemi basit tesadüfi ve küme örnekleme usulüyle seçilmiştir. Araştırmaya katılan öğretmenler bireysel olarak belirlenmemiş, çalıştıkları okullar basit tesadüfi örnekleme ile seçilmiş ve bu okullardaki öğretmenler çalışmaya dâhil edilmiştir (a.g.e). Araştırmaya katılan öğretmenlere ilişkin tanımlayıcı bilgiler Tablo 1'de yer almaktadir. 
Tablo 1. Katılımcilara Ait Demografik Bilgiler

\begin{tabular}{llll}
\hline Demografik Bilgiler & & $\mathrm{n}$ & $\mathbf{\%}$ \\
\hline \multirow{2}{*}{ Cinsiyet } & Kadın & 301 & 78,4 \\
\cline { 2 - 4 } & Erkek & 83 & 21,6 \\
\hline \multirow{3}{*}{ Yaş } & $21-30$ & 161 & 41,9 \\
\cline { 2 - 4 } & 31-40 & 113 & 29,4 \\
\cline { 2 - 4 } & 41 ve üzeri & 110 & 28,6 \\
\hline \multirow{3}{*}{ Eğitim } & Ön lisans & 61 & 15,9 \\
\cline { 2 - 4 } & Lisans & 303 & 78,9 \\
\cline { 2 - 4 } & Yük. Lisans & 20 & 5,2 \\
\hline \multirow{3}{*}{ Çalışma Süresi } & 1-5 Y1l & 137 & 35,7 \\
\cline { 2 - 4 } & 6-10 Yıl & 74 & 19,3 \\
\cline { 2 - 4 } & 10 Yil üzeri & 173 & 45,1 \\
\hline \multirow{3}{*}{ Okul Türü } & Okul Öncesi Resmi & 80 & 20,8 \\
\cline { 2 - 4 } & Okul Öncesi Resmi & 121 & 31,5 \\
\cline { 2 - 4 } & İlkokul Resmi & 143 & 37,2 \\
\cline { 2 - 4 } & İlkokul Özel & 40 & 10,4 \\
\hline
\end{tabular}

Tablo 1'de katılımcıların demografik bilgileri sunulmuştur. Katılımc1ların \%78,4'ü kadın, \%21,6'sı ise erkektir. Çalışmaya katılan öğretmenlerin çoğunluğu \%41.9 ile 21-30 yaş arasındadır. Eğitim düzeyi olarak ise büyük oranda \%78,9 ile çalışmaya katılan öğretmenlerin lisans mezunu olduğu görülmektedir. Çalışma süresi bakımından ise 1-5 yıl arasında olanlar $\% 35,7 ; 6-10$ yıl arasında olanlar \%19,3 ve 10 yıl ve üzerinde çalışmış olanlar ise $\% 45,1$ olarak belirlenmiştir.

\section{Verilerin Toplanması}

Araştırmada veri toplamak amacıyla, "Bireysel Yenilikçilik Ölçeği" (K1l1çer ve Odabaşı, 2010), araştırmacı tarafından geliştirilmiş olan "Kişisel Bilgi Formu" ve "Onamsız Öğrenme Tercihleri Formu" kullanılmıştır.

"Kişisel Bilgi Formu", çalışmaya dâhil edilen okul öncesi ve sınıf öğretmenlerinin; cinsiyet, yaş, öğrenim durumu, meslekte geçirilen süre ve çalıştığ okul türü değişkenlerine ilişkin bilgileri toplamak amacıyla araştırmacı tarafından geliştirilmiştir.

Onamsız Öğrenme Tercihleri Formu öğretmenlerin onamsız öğrenme tercihlerini belirlemek amacıyla araştırmacı tarafından oluşturulmuştur. Formda 25 farklı onamsız öğrenme seçeneği sunulmuş ve öğretmenlerden 
en çok kullandıkları yollardan beşini önem sırasına göre tercih etmeleri istenmiştir.

Öğretmenlerin bireysel yenilikçilik düzeylerinin belirlemek için Hurt, Joseph ve Cook'un geliştirdiği ve Kılıçer ve Odabaşı'nın (2010) Türkçeye uyarladığı "Bireysel Yenilikçilik Ölçeği” uygulanmıştır. Ölçme aracında 12 'si olumlu $(1,2,3,5,8,9,11,12,14,16,18$. ve 19 . maddeler) ve 8 'i olumsuz $(4,6,7,10,13,15,17$. ve 20. maddeler) ifadeler içeren 20 madde yer almaktadır. Ölçek beşli Likert tipinde olup cevaplar "Kesinlikle Katılmıyorum"' düzeyinden, "Kesinlikle Katılıyorum"' düzeyine doğru değişmektedir. Geçerlik analizi sonucunda alt boyutların ölçekteki varyansın yüzde 52.521'ini açıkladığ 1 tespit edilmiştir. Alt boyutlar için hesaplanan güvenirlik katsayıları ,66 ile ,82 arasında değişmektedir.

Öğretmenlerin bireysel yenilikçilik puanı şu şekilde hesaplanmaktadır: Mevcut 42 temel puan üzerine, pozitif maddelerin toplamından negatif maddelerin toplamı çıkarılıp kalan puan eklenmektedir. Ölçekten alınacak en düşük puan 14, en yüksek puan ise 94'tür. Elde edilen puana göre bireylerin yenilikçilik grupları belirlenmektedir. Toplamda elde edilen puan 80 'in üzerindeyse "Yenilikçi", 69 ve 80 arasındaysa "Öncü", 57 ve 68 arasındaysa "Sorgulayıc1", 46 ve 56 arasındaysa "Kuşkucu", 46 altındaysa "Gelenekçi" grubuna yerleştirilmektedir. Ölçme aracı yoluyla elde edilen toplam puana göre kişilerin yenilikçilik seviyeleri Yenilikçi, Öncü, Sorgulayıcı, Kuşkucu ve Gelenekçi olarak beş sınıfa ayrılmıştır.

\section{Verilerin Analizi}

Araştırma verileri 2018 yılı Ekim ve Kasım ayları içerisinde basılı ölçme araçları kullanılarak toplanmıştır. Veri toplamada gönüllülük esas alınmıştır. Veriler toplandıktan sonra öncelikle bilgisayar ortamına aktarılmıştır. Veri analizleri istatistik paket programı ile yapılmıştır. Tüm analizlerde anlamlılık düzeyi, ,05 olarak alınmıştır. Veri analizlerine göre kişilerin yenilikçilik seviyeleri Yenilikçi, Öncü, Sorgulayıcı, Kuşkucu ve Gelenekçi olarak beş sınıfa ayrılması sebebiyle sınıflandırma ölçek düzeyinde olan değişkenlerin analizi için Ki-kare testi, kullanılmıştır. Yenilikçi grubunda yer alan kişiler bir yenilik ortaya çıktığında sorgulamadan hemen kabul edenler; Öncü olanlar ise yeniliği benimsemede topluma önderlik edenler; Sorgulayıcılar ise yeniliğe karşı olmamasına rağmen yeniliklere 
oldukça temkinli yaklaşanlardır. Kuşkucular ise yeniliği kabul etme süreleri oldukça uzun olan veya yetersiz olanakları sebebiyle yenilikleri gereksiz gören bireylerdir. Gelenekçiler ise yenilikleri asla kabul etmeyen ve direnç gösterenlerdir.

\section{Bulgular}

Bu bölümde araştırmanın veri analizi sonucunda elde edilen bulgular sunulmuştur. Araştırmanın amacı doğrultusunda araştırma sorularına cevap verilmiştir.

Araştırmaya katılan öğretmenler öncelikle Bireysel Yenilikçilik Ölçeği puanlarına göre kategorilere ayrılmıştır. Bulgular incelendiğinde öğretmenlerin yenilikçilik sınıflarından en çok Sorgulayıcı ve Öncü seviyelerinde oldukları görülmektedir. Diğer üç yenilikçilik seviyesinde (Yenilikçi, Kuşkucu ve Geleneksel) olan öğretmenlerin toplamı gerek Sorgulayıcı ve gerekse Öncü olarak kendini nitelendiren öğretmenlerin sayısından oldukça azdır.

Tablo 2. Öğretmenlerin Yenilikçilik Düzeyleri

\begin{tabular}{llll}
\hline & & $\mathrm{f}$ & $\%$ \\
\hline & Yenilikçi & 54 & 14,1 \\
& Öncü & 142 & 37,0 \\
Yenilikçilik sınıfı & Sorgulayıcı & 147 & 38,3 \\
& Kuşkucu & 30 & 7,8 \\
& Gelenekçi & 11 & 2,9 \\
\hline Toplam (N) & & 384 & 100,0 \\
\hline
\end{tabular}

Tablo 2 incelendiğinde, araştırmaya katılan 384 öğretmenin yenilikçilik kategorilerine dağılımına göre öğretmenler en çok Sorgulayıcı (\%38,3), sonrasında Öncü (\%37), daha sonra Yenilikçi $(\% 14,2)$, Kuşkucu $(\% 7,8)$ ve Gelenekçi $(\% 2,9)$ kategorilerinde toplanmıştır.

Okul öncesi ve sınıf öğretmenlerinin bireysel yenilikçilik kategorilerine dağılımları incelenmiştir. 
Tablo 3. Okul Öncesi ve Sını Öğretmenlerinin Bireysel Yenilikçilik Profilleri

\begin{tabular}{llll}
\hline Branş & Yenilikçilik Düzeyi & $\mathrm{f}$ & $\%$ \\
\hline \multirow{4}{*}{ Okul Öncesi } & Yenilikçi & 25 & 12,4 \\
& Öncü & 75 & 37,3 \\
& Sorgulayıc1 & 88 & 43,8 \\
& Kuşkucu & 13 & 6,5 \\
& Gelenekçi & 0 & 0,0 \\
\hline Toplam & & 201 & 100,0 \\
\hline \multirow{4}{*}{ Sinıf Öğretmeni } & Yenilikçi & 29 & 15,8 \\
& Öncü & 67 & 36,6 \\
& Sorgulayıc1 & 59 & 32,2 \\
& Kuşkucu & 17 & 9,3 \\
Toplam & Gelenekçi & 11 & 6,0 \\
\hline X2=17,195, Sd $=4, \mathrm{p}=, 002$ & 183 & 100,0
\end{tabular}

Tablo 3'e bakıldığında Ki-kare testi sonuçlarına göre okul öncesi ve s1nıf öğretmenleri bireysel yenilikçilik kategorilerine göre istatistiki olarak anlamlı bir şekilde farklılaşmaktadır $\left(X^{2}=17,195, S d=4, p<, 05\right)$. Buna göre bireysel yenilikçiliğin Gelenekçi kategorisinde sadece sınıf öğretmenleri vardır. Sorgulayıcı ve Öncü kategorilerinde okul öncesi öğretmenlerinin oranı sınıf öğretmenlerinden daha yüksektir.

Bu bölümde, öğretmenlerin bireysel yenilikçilik düzeyleri cinsiyet, yaş, öğrenim durumu ve çalıştığı okul türü değişkenlerine göre incelenmiştir.

Tablo 4'te öğretmenlerin bireysel yenilikçilik düzeylerinin cinsiyete göre farklılaşıp farklılaşmadığını incelemek amacıyla her iki değişken türü de kategorik olduğu için ki-kare ilişki testi kullanılmıştır.

Tablo 4. Öğretmenlerin Yenilikçilik Düzeylerinin Cinsiyete Göre Karşılaştırılması

\begin{tabular}{lllllll}
\hline \multirow{2}{*}{ Yenilikçilik sınıfı } & \multicolumn{3}{c}{ Cinsiyet } & \multicolumn{5}{c}{ Erkek } & \multicolumn{2}{c}{ Toplam } \\
\cline { 2 - 6 } & \multicolumn{2}{c}{ Kadın } & \multicolumn{5}{c}{ f } & f & $\%$ & $\mathrm{f}$ & $\%$ \\
\hline Yenilikçi & 45 & 15,0 & 9 & 10,8 & 54 & 14,1 \\
Öncü & 107 & 35,5 & 35 & 42,2 & 142 & 37,0 \\
Sorgulayıcı & 118 & 39,2 & 29 & 34,9 & 147 & 38,3 \\
Kuşkucu & 26 & 8,6 & 4 & 4,8 & 30 & 7,8 \\
Gelenekçi & 5 & 1,7 & 6 & 7,2 & 11 & 2,9 \\
Toplam & 301 & 100,0 & 83 & 100,0 & 384 & 100,0 \\
\hline
\end{tabular}

Ki-kare testi sonuçlarına göre kadın ve erkek öğretmenlerin bireysel yenilikçilik kategorilerine dağılımı istatistiki olarak anlamlı bir şekilde 
farklılaşmaktadır $\left(X^{2}=10,115, S d=4, p<, 05\right)$. Bireysel yenilikçiliğin Gelenekçi kategorisinde erkek oranı daha yüksek iken Kuşkucu kategorisinde kadın oranı daha yüksektir. Ayrıca erkeklerin bireysel yenilikçilikte Öncü olma yüzdeleri kadınlara göre daha yüksektir.

Tablo 5'te öğretmenlerin bireysel yenilikçilik düzeylerinin yaş kategorilerine göre farklılaşıp farklılaşmadığını incelemek amacıyla her iki değişken türü de kategorik olduğu için ki-kare ilişki testi kullanılmıştır.

Tablo 5. Öğretmenlerin Yenilikçilik Düzeylerinin Yaşa Göre Göre Karşılaştırılması

\begin{tabular}{|c|c|c|c|c|c|c|c|c|}
\hline \multirow{3}{*}{ Yenilikçilik Sınıfı } & \multicolumn{6}{|c|}{ Yaş Grubu } & & \\
\hline & \multicolumn{2}{|c|}{$21-30$} & \multicolumn{2}{|c|}{$31-40$} & \multicolumn{2}{|c|}{41 ve üzeri } & \multicolumn{2}{|c|}{ Toplam } \\
\hline & $\mathrm{f}$ & $\%$ & $\mathrm{f}$ & $\%$ & $\mathrm{f}$ & $\%$ & $\mathrm{f}$ & $\%$ \\
\hline Yenilikçi & 19 & 11,8 & 21 & 18,6 & 14 & 12,7 & 54 & 14,1 \\
\hline Öncü & 64 & 39,8 & 40 & 35,4 & 38 & 34,5 & 142 & 37,0 \\
\hline Sorgulayıcı & 62 & 38,5 & 42 & 37,2 & 43 & 39,1 & 147 & 38,3 \\
\hline Kuşkucu & 13 & 8,1 & 8 & 7,1 & 9 & 8,2 & 30 & 7,8 \\
\hline Gelenekçi & 3 & 1,9 & 2 & 1,8 & 6 & 5,5 & 11 & 2,9 \\
\hline Toplam & 161 & 100,0 & 113 & 100,0 & 110 & 100,0 & 384 & \\
\hline
\end{tabular}

Ki-kare testi sonuçlarına göre öğretmenlerin bireysel yenilikçilik kategorilerine dağılımı yaş gruplarına göre istatistiki olarak anlamlı bir şekilde farklılaşma göstermemektedir $\left(X^{2}=6,735, S d=8, p>, 05\right)$.

Tablo 6. Öğretmenlerin Yenilikçilik Düzeylerinin Eğitim Durumuna Göre Karşılaştırılması

\begin{tabular}{llllllllll}
\hline \multirow{2}{*}{ Yenilikçilik sınıfi } & \multicolumn{1}{c}{ Ön-lisans } & \multicolumn{3}{c}{ Lisans } & \multicolumn{3}{c}{ Yüitim } & \multicolumn{2}{c}{ Toplam } \\
& \cline { 2 - 7 } & $\mathrm{f}$ & $\%$ & $\mathrm{~F}$ & $\%$ & $\mathrm{f}$ & $\%$ & $\mathrm{f}$ & $\%$ \\
\hline Yenilikçi & 1 & 1,6 & 51 & 16,8 & 2 & 10,0 & 54 & 14,1 \\
Öncü & 26 & 42,6 & 109 & 36,0 & 7 & 35,0 & 142 & 37,0 \\
Sorgulayıc1 & 27 & 44,3 & 111 & 36,6 & 9 & 45,0 & 147 & 38,3 \\
Kuşkucu & 5 & 8,2 & 23 & 7,6 & 2 & 10,0 & 30 & 7,8 \\
Gelenekçi & 2 & 3,3 & 9 & 3,0 & 0 & 0,0 & 11 & 2,9 \\
Toplam & 61 & 100,0 & 303 & 100,0 & 20 & 100,0 & 384 & 100,0 \\
\hline
\end{tabular}

$\mathrm{X}^{2}=11,006, \mathrm{Sd}=8, \mathrm{p}=, 201$

Tablo 6'da öğretmenlerin bireysel yenilikçilik düzeylerinin eğitim durumlarına göre farklılaşıp farklılaşmadığını incelemek amacıyla her iki değişken türü de kategorik olduğu için ki-kare ilişki testi kullanılmıştır. 
Ki-kare testi sonuçlarına göre öğretmenlerin bireysel yenilikçilik kategorilerine dağılımı eğitim durumlarına göre istatistiki olarak anlamlı bir şekilde farklılaşma göstermemektedir $\left(X^{2}=11,006, S d=8, p>, 05\right)$.

Tablo 7. Öğretmenlerin Yenilikçilik Düzeylerinin Okul Türüne Göre Karşılaştırılması

\begin{tabular}{|c|c|c|c|c|c|c|c|c|c|c|}
\hline \multirow{3}{*}{ Yenilikçilik sınıfı } & \multicolumn{8}{|c|}{ Okul Türü } & \multirow{2}{*}{\multicolumn{2}{|c|}{ Toplam }} \\
\hline & \multicolumn{2}{|c|}{ O.Ö. Devlet } & \multicolumn{2}{|c|}{ O.Ö. Özel } & \multicolumn{2}{|c|}{ İ.Ö. Devlet } & \multicolumn{2}{|c|}{ İ.Ö. Özel } & & \\
\hline & $\mathrm{f}$ & $\%$ & $\mathrm{f}$ & $\%$ & $\mathrm{f}$ & $\%$ & $\mathrm{f}$ & $\%$ & $\mathrm{f}$ & $\%$ \\
\hline Yenilikçi & 13 & 16,2 & 12 & 9,9 & 19 & 13,3 & 10 & 25,0 & 54 & 14,1 \\
\hline Öncü & 27 & 33,8 & 48 & 39,7 & 60 & 42,0 & 7 & 17,5 & 142 & 37,0 \\
\hline Sorgulayıcı & 32 & 40,0 & 56 & 46,3 & 40 & 28,0 & 19 & 47,5 & 147 & 38,3 \\
\hline Kuşkucu & 8 & 10,0 & 5 & 4,1 & 13 & 9,1 & 4 & 10,0 & 30 & 7,8 \\
\hline Gelenekçi & 0 & 0,0 & 0 & 0,0 & 11 & 7,7 & 0 & 0,0 & 11 & 2,9 \\
\hline Toplam & 80 & 100 & 121 & 100 & 143 & 100 & 40 & 100 & 384 & 100 \\
\hline
\end{tabular}

$\mathrm{X}^{2}=39,353, \mathrm{Sd}=12, \mathrm{p}=.000$

Tablo 7'de öğretmenlerin bireysel yenilikçilik düzeylerinin çalıştıkları okulun türüne göre farklılaşıp farklılaşmadığını incelemek için her iki değişken türü de kategorik olduğu için ki-kare ilişki testi kullanılmıştır.

Ki-kare testi sonuçlarına göre öğretmenlerin bireysel yenilikçilik kategorilerine dağılımı çalıştıkları okul türüne göre istatistiki olarak anlamlı bir şekilde farklılaşmaktadır $\left(X^{2}=39,353, S d=12, p<, 05\right)$.

Tablo 7' de bireysel yenilikçiliğin Gelenekçi kategorisinde bulunan bütün öğretmenler $(n=11)$ devlet ilkokullarında okullarında çalışmaktadır. Benzer şekilde Kuşkucu kategorisinde devlet okul öncesi ve devlet ilkokullarında okullarında çalışan öğretmenlerin oranı yüksektir. Sorgulayıcı kategorisinde en çok özel ilkokullarında okullarında çalışan öğretmenler bulunmaktadır. Aynı şekilde Yenilikçi kategorisinde de özel ilkokullarında okullarında çalışan öğretmenlerin oranı diğerlerinden çok daha yüksektir. Devlet okul öncesi öğretmenlerinin özel okul öncesi okullarındaki öğretmenlerden daha Yenilikçi olmaları dikkat çekicidir.

Veri toplama sürecinde öğretmenler beş onamsız öğrenme ortamını önem siralarına göre tercih etmişlerdir. Birinci onamsız öğrenme ortamları tercihlerine göre, tercihler üç ana kategoride toplanmıştır. Sosyal onamsız öğrenme ortamı (aile, arkadaşlar vb), Teknolojik onamsız öğrenme ortamları (internet, akıllı telefon vb.) ve mekânsal onamsız öğrenme ortamları (botanik bahçesi, müzeler, oyun parkları vb.) olarak üç 
başlık altında toplanmıştır. Öğretmenlerin onamsız öğrenme ortamı tercihleri sırasıyla onların yenilikçilik kategorilerine göre incelenmiştir.

Tablo 8. Öğretmenlerin İlk Onamsız Öğrenme Ortamı Tercihleri

\begin{tabular}{|c|c|c|c|c|c|c|c|c|c|c|c|c|}
\hline \multirow{3}{*}{$\begin{array}{l}\text { Onamsız } \\
\text { Öğrenme } \\
\text { Ortamı }\end{array}$} & \multicolumn{12}{|c|}{ Yenilikçilik sınıfı } \\
\hline & \multicolumn{2}{|c|}{ Yenilikçi } & \multicolumn{2}{|c|}{ Öncü } & \multicolumn{4}{|c|}{ Sorgulayıcı Kuşkucu } & \multicolumn{2}{|c|}{ Gelenekçi } & \multicolumn{2}{|c|}{ Toplam } \\
\hline & $\mathrm{f}$ & $\%$ & $\mathrm{f}$ & $\%$ & $\mathrm{f}$ & $\%$ & $\mathrm{f}$ & $\%$ & $\mathrm{f}$ & $\%$ & $\mathrm{f}$ & $\%$ \\
\hline Sosyal & 41 & 13,9 & 109 & 36,9 & 114 & 38,6 & 24 & 8,1 & 7 & 2,4 & 295 & 76,8 \\
\hline Teknolojik & 10 & 7,4 & 26 & 5,6 & 24 & 6,1 & 2 & 3,3 & 3 & 18,2 & 24 & 6,2 \\
\hline Mekânsal & 3 & 11,1 & 7 & 12,7 & 9 & 10,2 & 4 & 3,3 & 1 & 9,1 & 41 & 10,7 \\
\hline Toplam & 54 & 100 & 142 & 100 & 147 & 100 & 30 & 100 & 11 & 100 & 384 & 100 \\
\hline
\end{tabular}

Tablo 8' de yüzde dağılımlarına bakıldığında, Yenilikçi, Öncü, Sorgulayıcı, Kuşkucu ve Gelenekçi grupta yer alan öğretmenlerin benzer onamsız öğrenme ortamlarından faydalandıkları söylenebilir. Tüm gruplarda Sosyal onamsız öğrenme ortamı ilk sırada yer almaktadır. Ki-kare testi sonuçlarına göre öğretmenlerin onamsız öğrenme ortamı tercihleri istatistiki olarak anlamlı bir şekilde farklılaşma göstermemektedir $\left(X^{2}=6,130, S d=20\right.$, $\mathrm{p}>, 05)$.

\section{Tartışma ve Sonuç}

Araştırmanın amaçları doğrultusunda öğretmenlere uygulanan ölçekten elde edilen bulguların analiz edilmesinin ardından şu sonuçlara varılmıştır:

Araştırmaya katılan öğretmenlerde ise Yenilikçiler yüzde 14.2, Öncüler yüzde 37, sorgulayıcılar yüzde 38.3, Kuşkucular yüzde 7.8 ve Gelenekçiler yüzde 2.9 oranında görülmüştür. Ancak, Rogers'a (2003) göre bir toplumda Yenilikçiler yüzde 2.5, Öncüler yüzde 13.5, Sorgulayıcılar yüzde 34, Kuşkucular yüzde 34 ve Gelenekçiler yüzde 16 oranındadır. Bu sonuçlara göre araştırmaya katılan öğretmenlerin özellikle Yenilikçi ve Öncü grubunda toplum ortalamasının çok üstünde oldukları anlaşılmaktadır. $\mathrm{Bu}$ da öğretmenlerin yenilikleri hayatlarına uygulama konusunda oldukça istekli oldukları söylenebilir. Bu sonucun nedeni eğitim seviyesinin yüksek olmasından da olabilir. Yenilikçi, Öncü ve Sorgulayıcılar eğitim 
seviyesi yüksek kişilerden oluşmaktadır (Rogers, 2003). Kaya (2017) tarafından biyoloji öğretmenleri üzerine yapılan araştırmada da Yenilikçi, Öncü ve Sorgulayıcı grubun yüzdesi oldukça yüksek çıkmıştır. Bitkin (2012), Yılmaz (2013) ve Tırpan (2016) tarafından öğretmen adayların üzerine yapılan çalışmalarda da bu araştırmada ortaya çıkan yenilikçilik sınıflarının yüzdeleri yaklaşık olarak benzer çıkmıştır.

Bireysel yenilikçiliğin tüm alt kategorilerinde okul öncesi öğretmenleri ile sınıf öğretmenleri arasında istatistiki olarak anlamlı bir farklılık saptanmamıştır. Bireysel yenilikçiliğin Gelenekçi kategorisinde sadece ilkokul sınıf öğretmenleri vardır. Sorgulayıcı ve Öncü kategorilerinde okul öncesi öğretmenlerinin oranı sınıf öğretmenlerinden daha yüksektir. $\mathrm{Bu}$ sonuçlara göre okul öncesi öğretmenlerin daha Yenilikçi oldukları görülebilir. Gürbüz (2015) çalışmasında, bu araştırmandan farklı olarak farklı kademelerde görev yapan öğretmenler arasında yenilikçilik açısından bir fark tespit etmemiştir. Başaran ve Keleş de (2015) benzer sonuca ulaşmıştır. Tırpan'ın (2016), İncik ve Yanpar-Yelken'in (2011) yaptıkları öğretmen adayları üzerindeki araştırmalarda, değişik bölümlerde okuyanlar arasında yenilikçilik düzeyleri arasında fark bulunmamıştır.

Kadın ve erkek öğretmenlerin bireysel yenilikçilik kategorilerine dağ1lımı istatistiki olarak anlamlı bir şekilde farklılaşmaktadır. Buna göre bireysel yenilikçiliğin Gelenekçi kategorisinde erkek oranı daha yüksek iken Kuşkucu kategorisinde kadın oranı daha yüksektir. Ayrıca erkeklerin bireysel yenilikçilikte Öncü olma ihtimali kadınlara göre daha yüksektir. Gürbüz (2015) çalışmasında, bu araştırmandan farklı olarak kadın ve erkek öğretmenler arasında yenilikçilik açısından bir fark tespit etmemiştir. Kaya da (2017) kadın ve erkek öğretmenler arasında bir fark tespit etmemiştir. Tırpan'ın (2016) öğretmen adayları üzerinde yaptığı araştırmada da kız ve erkekler arasında fark bulunmamıştır. Yılmaz ve arkadaşları (2014) bu araştırmayla benzer şekilde kızların erkeklere göre daha Yenilikçi olduğunu tespit etmiştir.

Öğretmenlerin bireysel yenilikçilik kategorilerine dağılımı yaş gruplarına, eğitim durumlarına ve çalışma süresine göre istatistiki olarak anlamlı düzeyde farklılaşmamaktadır. Buna göre yenilikçiliğin, öğretmenler arasında yaşla ilgisi olmadığı söylenebilir. Aynı şekilde yeni mezun veya tecrübeli öğretmenler benzer biçimde tecrübeli olabilmektedir. Gürbüz 
(2015) çalışmasında, bu araştırmaya benzer biçimde yaşa göre öğretmenler arasında yenilikçilik açısından bir fark tespit etmemiştir.

Öğretmenlerin bireysel yenilikçilik kategorilerine dağılımı çalıştıkları okul türüne göre istatistiki olarak anlamlı bir şekilde farklılaşmaktadır. Buna göre bireysel yenilikçiliğin Gelenekçi kategorisinde bulunan bütün öğretmenler devlet ilkokullarında çalışmaktadır. Benzer şekilde Kuşkucu kategorisinde devlet okul öncesi ve devlet ilkokullarında çalışan öğretmenlerin oranı yüksektir. Sorgulayıcı kategorisinde en çok özel ilkokullarda çalışan öğretmenler bulunmaktadır. Aynı şekilde Yenilikçi kategorisinde de özel ilkokullarında çalışan öğretmenlerin oranı diğerlerinden çok daha yüksektir. Devlet okul öncesi öğretmenlerinin özel okul öncesi okullarındaki öğretmenlerden daha Yenilikçi olmaları dikkat çekicidir. Bu bulgular oldukça ilgi çekicidir. Özel okulda çalışan öğretmenlerin daha yenilikçi olmaları, özel okulların sürekli bir farklı olma arayışında olmaları ve bu konuda öğretmenlerden beklentileri olmasından kaynaklanıyor olabilir.

Öğretmenlerin yenilikçilik puanları en önemli buldukları onamsız öğrenme ortamı tercihlerine göre bir farklılık göstermemektedir. Sadece kitap okuma düzeyi Öncü grupta daha yüksektir. Bitkin (2012) tarafından öğretmen adayları üzerinde yapılan çalışmada, kitap okuma sayısı yüksek olanlarda yenilikçiliğin de daha yüksek olduğu tespit edilmiştir. Aynı şekilde bir yayını takip edenlerde yenilikçilik daha yüksektir. Yenilikçilerin bilgi edinme becerileri daha yüksektir. Çalışmaya katılan öğretmenlerin Yenilikçi, Öncü, Sorgulayıcı, Kuşkucu ve Gelenekçi grupta yer almasına rağmen, benzer onamsız öğrenme ortamlarından faydalandıkları söylenebilir. Tüm gruplarda Sosyal onamsız öğrenme ortamı ilk sırada yer almaktadir.

Araştırmanın amaçları doğrultusunda öğretmenlere uygulanan ölçekten elde edilen bulguların analiz edilmesinin ardından şu önerilerde bulunulabilir. Öğretmenlerin yenilikçilik puanları oldukça yüksektir. Bununla birlikte düşük puanlı olanlar da bulunmaktadır. Bu öğretmenlerin eğitim sistemine getirilecek yeniliklerde karşı çıma ihtimali bulunmaktadır. Yenilikçilerin tercihlerine göre daha yenilikçi onamsız öğrenme ortamları hazırlanabilir. 
Genel olarak öğretmenlerin yenilikçilik düzeylerinin artırılmasına yönelik çalışmalar yapılmalıdır. Program değişimi, teknolojik yenliklerin sınıfa getirilmesi gibi durumlarda Kuşkucu ve Gelenekçi öğretmenler göz önüne alınarak, onamsız öğrenme ortamlarının öğretimlerine sağlayacağı katkılar konusunda eğitim almaları sağlanabilir Program bazında olmasa dahi her öğretmen kendi sınıfında yenilikleri uygulama konusunda cesur olmalıdır. Okul öncesi öğretmenleri sınıf öğretmenlerinden daha yenilikçi olarak tespit edilmiştir. Bu sonucun nedenlerine ilişkin yeni bir araştırma yapılabilir. Benzer problemlere yanıt arayan çalışmaların karma yöntemle derinlemesine araştırılmasında yarar olduğu değerlendirilmektedir.

Onamsız öğrenme ortamlarının kullanımı konusunda öğretmen tercihlerini ve nedenlerini açıklamak amacıyla farklı okul düzeylerinde, farklı dersler için çalışmalar yapılmalıdır. 


\section{EXTENDED ABSTRACT}

\section{Investigating Pre-school and Primary School Teachers' Preferences of Informal Learning Environments and Their Individual Innovativeness Levels \\ *

\author{
Kamil Arif Kırkıç - Buşra Topal \\ Istanbul Sabahattin Zaim University, Ministry of National Education
}

Due to new technological developments, new ideas are put forward, and the old ones change as a result of the events in science. These improvements are innovation; the transfer of innovation to life is called innovativeness (Handa and Gupta, 2009). Individual innovativeness refers to the differences that individuals put forward in terms of innovation. Not all individuals are equally Innovators. Rogers (1995) divided individuals into five groups as Innovators, Early Adopters, Early Majority, Late Majority, and Laggards in terms of their level of innovation. Those who accept an innovation without question are Innovators; while those who come before the society are classified as Early Adopters, the Early Majority members are not cautious but a novelty. Late Majority group members are those who do not accept innovation for a long time or see it as unnecessary because there is no possibility. Laggards oppose innovation, with the suspicion that they will break their ties with the past. There are lots of studies done about relationship between innovation and different variables as national (Bitkin, 2012; Demirel and Seçkin 2008; Erdil et al., 2017; Gürbüz, 2015; Kaya, 2017; Özçatalbaş, 2014; Tırpan, 2016; Yılmaz, 2013) and international in the literature (Davis et al., 1989; Handa and Gupta, 2009; Moore and Benbasat, 1991; Rogers, 2003; Surry \& Brennan 1998; Venkatesh, Thong and $\mathrm{Xu}, 2012)$. Innovators individuals can integrate their lives and innovation, and sometimes they can benefit from different learning environments because they are innovators in addition to performing their learning processes in schools, institutes that are traditional ways. 
This study aimed to determine the levels of individual innovativeness and informal learning environments of pre-school and primary school teachers as well as to determine the informal learning environments they prefer according to individual innovativeness levels.

In this research, answers to the following questions were sought:

- What is the distribution of preschool and classroom teachers by individual innovativeness categories?

- Is there any difference between preschool and classroom teachers in terms of individual innovativeness levels?

- Do teachers' levels of innovativeness differ according to the various characteristics of teachers?

- Which informal learning environments do teachers prefer according to their level of innovativeness?

In this research, a descriptive survey model, which is within the scope of quantitative research design, was used. In this model, an existing situation is described as being in a period without any intervention (Büyüköztürk et al., 2017). In this study, individual innovativeness levels and informal learning environment preferences of teachers were measured, and it was determined how the informal learning environment preferences of teachers changed according to their individual innovativeness levels.

The population of the research is 7644 pre-school and primary school teachers working in public or private schools, and 384 teachers are the sample which was selected by simple random sampling. In this type of sampling, every individual in the population has the same chance of participating in the sample (Ibid).

After the analysis of the findings obtained from the scale applied to the students, the following conclusions were reached:

According to Rogers (2003), in a society, Innovators account for $2.5 \%$, Early Adopters 13.5\%, Early Majority $34 \%$, Late Majority $34 \%$, and Laggards $16 \%$. For the teachers who participated in the research, innovators were $14.2 \%$, Early Adopters 37\%, Early Majority 38.3\%, Late Majority $7.8 \%$, and Laggards $2.9 \%$. According to these results, it is understood that the teachers participating in the research are above the average of the society, especially in the Innovators and Early Adopters group. It can be said 
that teachers are very eager to apply innovations to their lives. This eagerness may be due to the high level of education. Innovators, Early Adopters, and Early Majority individuals are composed of high level of education (Rogers, 2003). In the study conducted by Kaya (2017) on biology teachers, the percentages of Innovators, Early Adopters, and Early Majority groups were quite high. Bitkin (2012), Yilmaz (2013), and Tirpan (2016) reached similar results on prospective teachers.

Preschool and classroom teachers differ significantly in terms of individual innovativeness categories. In the laggard's category of individual innovativeness, there are only primary school classroom teachers. The proportion of preschool teachers in the Early Majority and the Early Adopters categories is higher than that of classroom teachers. According to these results, it can be seen that preschool teachers are more Innovators. Gürbüz (2015) found no difference in terms of innovation among teachers working at different levels in this study. Basaran and Keles (2015) reached similar results. Tirpan (2016), İncik and Yanpar-Yelken (2011) did not find any difference between prospective teachers studying in different departments.

The distribution of male and female teachers into individual innovativeness categories is statistically different. Accordingly, the rate of men is higher in the Laggards category of individual innovativeness, whereas the percentage of women is higher in the Late Majority category. Men are also more likely to be Early Adopters in individual innovativeness than women are. In his study, Gürbüz (2015), unlike this study, did not find a difference between male and female teachers in terms of innovativeness. Kaya (2017) also found no difference between male and female teachers. Tirpan (2016) did not see any difference between boys and girls in their research on prospective teachers. Yilmaz et al. (2014) found that girls were more innovators than boys in their study were.

The distribution of teachers in individual innovativeness categories does not show statistically significant differences according to age groups, educational backgrounds, and working time. Accordingly, it can be said that innovativeness is not related to age among teachers. Gürbüz (2015) did not find a significant difference in terms of innovativeness among teachers by age similar to this study. 
The distribution of teachers in individual innovativeness categories differs statistically according to the type of school they work - accordingly, all teachers in the laggard's group of individual innovativeness work in public primary schools. Similarly, the proportion of teachers working in public preschool and state primary schools is high in the Late Majority category. In the type of the Early Majority, teachers working in private primary schools are the most common. Similarly, the proportion of teachers working in private primary schools in the Innovators category is much higher than the others are. It is noteworthy that public preschool teachers are more innovators than teachers in private preschools are. These findings are quite impressive. The fact that teachers working in private schools are more Innovators may be because private schools continuously seek to be different and have high expectations from teachers.

Teachers' innovativeness scores do not differ according to the preferences of the informal learning environment they find most important. Although the teachers involved in the study were included in the Innovators, Early Adopters, Early Majority, Late Majority, and Laggards group, it can be said that they benefited from similar informal learning environments. The social informal learning environment takes first place in all groups.

Following the analysis of the findings obtained from the scale applied to teachers for the research, the following suggestions can be made. Teachers' innovativeness scores are quite high. However, there are also lowrated ones. There is a possibility that these teachers may oppose the innovations that will be introduced to the education system. In general, efforts should be made to increase teachers' level of innovativeness. In the case of program change and bringing technological innovations to the classroom, teachers from Late Majority and Laggards may be educated about the contributions of informal learning environments to their teaching. Preschool teachers were identified as more Innovators than homeroom teachers. A new study of the causes of this outcome can be made. It is considered that it is useful to do in-depth investigations of studies seeking answers to similar problems.

Studies should be conducted for different courses at different school levels to explain teacher preferences and reasons for the use of informal learning environments. 


\section{Kaynakça / References}

Bennett, E.E. (2012). A four-part model of informal learning: Extending Schugurensky's conceptual model. In Proceedings of the Adult Education Research Conference. Saratoga Springs, NY: AERC. 08.09.2018 tarihinde http://www.adulterc.org/Proceedings/2012/papers/bennett.pdf adresinden erişilmiştir.

Bitkin, A. (2012). Öğretmen adaylarının bireysel yenilikçilik düzeyleri ile bilgi edinme becerileri arasındaki ilişki. Yayınlanmamış yüksek lisans tezi Harran Üniversitesi, Urfa Sosyal Bilimler Enstitüsü.

Büyüköztürk, Ş., Çakmak, E. K., Akgün, Ö. E., Karadeniz, Ş., ve Demirel, F. (2017). Bilimsel araştırma yöntemleri. Ankara: Pegem A Yayıncılık.

Çavuş, R., Umdu Topsakal, Ü. ve Öztuna Kaplan, A. (2013). İnformal öğrenme ortamlarının çevre bilinci kazandırmasına ilişkin öğretmen görüşleri: Kocaeli bilgievleri örneği. Pegem Eğitim ve Öğretim Dergisi, 3(1), 15-26.

Davis, F. D., Bagozzi, R. P., ve Warshaw, P. R. (1989). User acceptance of computer technology: a comparison of two theoretical models. Management science, 35(8), 982-1003.

Demir, K. (2006). Rogers' 1 yeniliğin yayılması teorisi ve internetten ders kayd. Kuram ve Uygulamada Ĕ̆itim Yönetimi Dergisi, 12(3), 367-392.

Demirel, Y., and Seçkin, Ö. G. Z. (2008). Bilgi ve bilgi paylaşımının yenilikçilik üzerine etkileri. Çukurova Üniversitesi Sosyal Bilimler Enstitüsü Dergisi, 17(1), 189-202.

Eraut, M. (2004). Informal learning in the workplace. Studies in Continuing Education, 26(2), 247-273.

Erdil, E., Pamukçu, M. T., Akçomak, İ. S., ve Tiryakioğlu, M. (2017). Bilgi, bilim, teknoloji ve yenilik: Kavramsal tartışma. ODTÜ TEKPOL Bilim ve Teknoloji Politikaları Araştırma Merkezi, TEKPOL Working Paper Series STPS-WP-16/01, Ankara 30.08.2019 tarihinde http://stps.metu.edu.tr/sites/stps.metu.edu.tr/files/WP\% 2016\% 3A01_1.pdf adresinden erişilmiştir.

Gürbüz, O. (2015). Öğretmen adaylarının yenilikçilikleri ve problem çözme becerileri arasındaki ilişkinin incelenmesi: ÇOMÜ eğitim fakültesi örneği. Yayınlanmamış yüksek lisans tezi. Çanakkale On sekiz Mart Üniversitesi, Çanakkale Eğitim Bilimleri Enstitüsü. 
Gürbüz, H., Kışoğlu, M. ve Erkol, M. (2007). Biyoloji öğretmen adaylarının çevreye yönelik tutumlarının informal ve formal eğitim ortamları açısından değerlendirilmesi. Atatürk Üniversitesi Bayburt Eğitim Fakültesi Dergisi, 2(3), 74-84.

Hager, P. and Halliday, J. (2009). Recovering Informal Learning: Wisdom, Judgement and Community. Netherlands: Springer.

Handa, M. and Gupta, N. (2009). Gender influence on the innovativeness of young urban Indian online shoppers. VISION-the Journal of Business Perspective, 13(2), 25-32.

İncik, E. Y., ve Yelken, T. Y. (2011). İlköğretim öğretmen adaylarının yenilikçilik düzeyleri: Mersin Üniversitesi örneği. I. Uluslararası Ĕ̆itim Programları ve Öğretim Kongresi, 05-08.

Kaya, S. (2017). Biyoloji öğretmenlerinin bireysel yenilikçilik düzeylerinin incelenmesi. Yayınlanmamış yüksek lisans tezi. Dicle Üniversitesi, Diyarbakır Eğitim Bilimleri Enstitüsü.

Kılıçer, K., ve Odabaşı, H. F. (2010). Bireysel yenilikçilik ölçeği BYÖ Türkçeye uyarlama geçerlik ve güvenirlik çalışması. Hacettepe Üniversitesi Eğitim Fakültesi Dergisi, 38 (10), 150-164.

McGivney, V. (2006). Informal Learning-The Challenge for Research. In (R. Edwards, J. Gallacher and S. Whittaker Eds.). Learning Outside the Academy - International Research Perspectives on Lifelong Learning. (p.11-23). USA: Routledge.

Moore, G. C., and Benbasat, I. (1991). Development of an instrument to measure the perceptions of adopting an information technology innovation. Information systems research, 2(3), 192-222.

Oktay, A. (2009). Ĕğitim bilimine giriş. Ankara: Pegem Akademi.

Özçatalbaş, O. (2014) Yeniliklerin yayılması. 28.11.2018 tarihinde https://www.researchgate.net/profile/Orhan Oezcatalbas/publication/311125321_Yeniliklerin_Yayilmasi/links/583e9c4608ae61f75dc7125b/Yeniliklerin-Yayilmasi.pdf adresinden erişilmiştir.

Rogers, E. M. (1995). Diffusion of innovations. New York: Free Press.

Rogers, E. M. (2003). Diffusion of innovations. (Fifth ed.). New York: Free Press.

Schugurensky, D. (2000). The forms of informal learning: Towards a conceptualization of the field. NALL Working Paper, 19. 2.12.2018 tarihinde 
https://tspace.library.utoronto.ca/bitstream/1807/2733/2/19formsofonamsız.pdf adresinden erişilmiştir.

Surry, D. W., and Brennan, J. P. (1998). Diffusion of instructional innovations:

Five important, unexplored questions. 10.12.2018 tarihinde https://files.eric.ed.gov/fulltext/ED422892.pdf adresinden erişilmiştir.

Şeker, S. E. (2014). Yenilik (Innovation). YBS Ansiklopedi, 1, 20-24.

Şimşek-Laçin, C. (2011). Okul dışı öğrenme ortamları ve Fen eğitimi. In (A. İ. Şen, A. E. Bozdoğan, E. A. Yiğit, F. B. Kıyıcı, F. V. Uzun, H. Nuhoğlu, Ö. Keleş, Eds.). Fen öğretiminde okul dışı öğrenme ortamlar (p.1-24). Ankara. Pegem Akademi.

Tırpan, M.S. (2016). Beden eğitimi ve spor yüksekokulu öğrencilerinin bireysel yenilikçilik ve genel öz yeterlilikleri arasındaki ilişkinin incelenmesi. Yayınlanmamış Yüksek Lisans Tezi. Ege Üniversitesi, İzmir Sağlık Bilimleri Enstitüsü.

Türkmen, H. (2015). İlkokul öğretmenlerin sinıf dışı ortamlardaki fen öğretimine bakış açıları. Journal of European Education, JEE, 5(2), 47-55.

Venkatesh, V., Thong, J. Y., and Xu, X. (2012). Consumer acceptance and use of information technology: extending the unified theory of acceptance and use of technology. MIS quarterly, 36 157-178. doi:10.2307/41410412

Yılmaz, F., Soğukçeşme, G., Ayhan, N., Tuncay, S., Sancar, S., and Deniz, Y. M. (2014). İlköğretim bölümü öğretmen adaylarının mesleki yenilikçilik düşüncelerinin çeşitli değişkenler açısından incelenmesi. Mustafa Kemal Üniversitesi Sosyal Bilimler Enstitüsü Dergisi, 11(27).

Yllmaz, N. (2013). An investigation of preservice early childhood teachers? Levels of individual innovativeness and perceived attributes of instructional computer use. Yayınlanmamış yüksek lisans tezi. ODTÜ, Ankara Sosyal Bilimler Enstitüsü.

\section{Kaynakça Bilgisi / Citation Information}

Kırkıç, K. A. ve Topal, B. (2019). Okul öncesi ve ilkokul sınıf öğretmenlerinin bireysel yenilikçilik düzeyleri ve onamsız öğrenme ortamları tercihlerinin incelenmesi. OPUS-Uluslararası Toplum Araştırmaları Dergisi, 14(20), 1626-1648. DOI: 10.26466/opus.598991 